\title{
TURISMO Y CONSUMO DEL ESPACIO URBANO EN BARCELONA. ANÁLISIS DE LA RELACIÓN RESIDENTE-TURISTA EN EL BARRIO DE LA BARCELONETA
}

\author{
Miriam-Hermi Zaar* \\ Universidad de Barcelona \\ https://orcid.org/0000-0002-1717-8118 \\ Maria Aparecida Pontes da Fonseca** \\ Universidade Federal do Rio Grande do Norte. Brasil \\ https://orcid.org/0000-0003-1683-2332
}

\section{RESUMEN}

Las políticas públicas y el turismo masivo han impulsado nuevas lógicas urbanísticas asociadas al proceso de gentrificación, en las que se incluyen la especulación inmobiliaria y la mercantilización del espacio público. Para la contextualización de esta problemática, que implica la relación entre residentes, turistas y agentes inmobiliarios/turísticos se eligió el barrio barcelonés de La Barceloneta, en cuyo escenario se observa cómo la demanda de los visitantes discrepa de las necesidades de los residentes y cómo las actividades turísticas afectan la vida cotidiana de sus ciudadanos. Asimismo, se evalúan los impactos socio territoriales que causan un mayor nivel de rechazo vecinal y que han sido motivo de reivindicaciones y protestas que exigen la reglamentación de las viviendas de uso turístico (VUT) y del uso del espacio público, lo que se ha conseguido, aunque parcialmente, a través de la aprobación del PEUAT.

Palabras clave: Relación residente-turista; Turistificación; Viviendas de uso turístico; Consumo del espacio público; La Barceloneta, Barcelona.

Fecha de recepción: 13 de febrero de 2018

Fecha de aceptación: 28 de septiembre de 2018

* Departamento de Geografía. Universidad de Barcelona. Calle Montalegre 6. 08001 BARCELONA (España).E-mail:miriamzaar@yahoo.es

**Departamento de Geografía. Universidade Federal do Rio Grande do Norte. Campus Universitário. 59.078-970 NATAL (Brasil). E-mail: mpontesfonseca@gmail.com 


\title{
Tourism and consumption of urban space in Barcelona. Analysis of the resident-tou- rist relationship in the La Barceloneta neighbourhood
}

\begin{abstract}
Public policies and mass tourism have promoted new urban logic associated with the gentrification process, which includes real estate speculation and the commercialization of public space. For the contextualization of this problem, which implies the relationship between residents, tourists and real estate agents / tourists, was chosen the La Barceloneta neighbourhood, in whose scenario it is observed how the demand of the visitors disagrees with the needs of the residents and how tourism activities affect the daily lives of its citizens. Likewise, this paper evaluates the socio-territorial impacts that cause a greater level of neighbourhood rejection, as well as claims and protests that require the regulation of housing for tourist use (VUT) and the use of public space, which has been achieved, although not entirely, through the approval of the PEUAT.
\end{abstract}

Key words: Tourist-resident relationship; Turistification; 'Homes for tourist use'; Consumption of public space; La Barceloneta, Barcelona.

\section{INTRODUCCIÓN}

En el último siglo muchas ciudades se han proveído de atributos que las han convertido en lugares de atracción turística. Un ejemplo de este proceder es la ciudad de París, cuyos procesos de modernización, realizados durante la segunda mitad del siglo XIX y en el siglo $\mathrm{XX}$, impulsaron nuevas lógicas urbanísticas por las que sus proyectos arquitectónicos, espacios de cultura y de ocio se transformaron en 'objeto de deseo' de más de 40 millones de turistas que la visitan anualmente.

Para ello, fueron determinantes el aumento del poder adquisitivo de los trabajadores, la institución de las vacaciones, el desarrollo de los medios de comunicación y de transporte e, igualmente, la adopción del modelo económico neoliberal y la reestructuración de las ciudades tradicionalmente fabriles hacia una economía volcada al sector servicios. También han coadyuvado las transformaciones socioculturales que valoran el hábito de viajar, con diferentes objetivos, como profesionales, de intercambio cultural, de ocio y otros.

Como resultado, de esta nueva dinámica en la que conjugan la internacionalización de las actividades financieras y la especulación inmobiliaria y del suelo urbano, las actividades turísticas pasaron a representar un importante segmento del Producto Interior Bruto de muchas ciudades globales. En 2016, el PIB turístico de Londres alcanzó el 19\%, el de Barcelona un 15\%, el de París un 8\% y el de Madrid, un 7,7\% (Hosteltur, 13/11/2017).

En este proceso, la organización del consumo y del espacio, a través de la urbanización, se volvió esencial para la dinámica del capitalismo, convirtiéndose en un instrumento por excelencia, para absorber el excedente del capital. Grandes cantidades de capital asociado 
han sido puestos en movimiento y "creados nuevos paisajes donde el capital circula en formas contradictorias" (Harvey, 2011), a través de mecanismos en los que las instituciones públicas se convierten en un importante copartícipe, sin considerar las necesidades de la ciudadanía.

En esta línea de actuación,

"y como parte de un nuevo orden económico y territorial, en el que el 'espacio-mercancía' se sobrepone a los 'espacios sociales' en los que se realiza la vida, las políticas de incentivo al proceso de gentrificación en los barrios antiguos de las ciudades han contribuido a expulsar sus vecinos y destruido su 'urbanidad', y en su lugar se han creado zonas estrategias que estimulan nuevos usos y estilos de vida vinculados a la industria del consumo, al ocio, al turismo y al beneficio de algunos grupos sociales" (Zaar, 2017a, p. 2-3).

Esta postura crítica ante la actividad turística está vinculada al hecho de que, mientras para los residentes o vecinos (hosts), la ciudad conforma un lugar de producción de la vida, donde sus habitantes materializan su cotidiano, y con él desarrollan una relación de identidad y de pertenencia; para la mayoría de los visitantes (guests), la ciudad constituye un lugar de consumo, de placer y disfrute.

Esta lógica parte del hecho de que "mientras el turista observa o acumula objetos y espacios como 'nutrición turística', el residente los valora como parte esencial de su condición de ser en-el-mundo (Hiernaux, González, 2014, p. 65). Estas dos percepciones se vuelven mucho más evidente cuando el consumo masivo de los territorios aumenta la presión y se produce una disputa por su uso entre estos segmentos sociales. Se crea una condición propicia para que los elementos contradictorios que conforman este proceso generen conflictos, desencadenando, en algunos casos, una actitud de rechazo vecinal hacia los visitantes.

Asimismo, los turistas se convierten en agentes centrales, ya que no hay destino turístico sin turistas. La producción del espacio ocurre teniendo en cuenta las necesidades y las aspiraciones de aquellos que pagan para consumir dicha destinación turística.

Los objetivos de este texto son a) analizar la coyuntura en la que se ha desarrollado el proceso de planificación urbana de Barcelona y cómo ésta, a través del proceso de turistificación de la ciudad, ha puesto en marcha los mecanismos que fomentan la gentrificación y, b) poner énfasis en las principales consecuencias socio territoriales de este proceso (la pérdida de la vivienda, la expulsión vecinal y la fuerte presión del espacio público) que han supuesto la pérdida de calidad de vida de la población de los barrios céntricos. Se trata de un escenario en el que se han generado conflictos y aumentado el descontento vecinal por las actividades turísticas, lo que los ha llevado a organizarse en movimientos de resistencia y de reivindicación.

El enfoque central parte de la premisa de que la base de los conflictos entre residentes, visitantes y agentes inmobiliarios está en los intereses enfrentados por el uso del territorio. Esto es así porque, a medida que el flujo turístico se intensifica, el proceso de desterritorialización de los residentes y de territorialización de los foráneos se hace más evidente.

La estructura y propuesta metodológica, comprende un estudio bibliográfico introductorio en el que se revisa, cómo el impacto de la actividad turística sobre el lugar de 
destino ha sido tratado, en las cuatro últimas décadas, en las que esta actividad ha pasado por una significativa transformación y el número de turistas ha alcanzado récords ${ }^{1}$. En el mismo se señala cómo las actividades turísticas interaccionan con el entorno geográfico y promueven cambios en la estructura socio espacial de los territorios.

A continuación, se elabora un análisis a partir de algunas perspectivas que se revelan imprescindibles para la aprehensión de un fenómeno cada vez más presente en las ciudades, a causa de la difusión del turismo de masas: la percepción de los residentes con relación a la actividad turística y a los turistas, en la que se evidencia, un sentimiento y una actitud de rechazo, aunque en grados distintos, y vinculados a aspectos diversos.

Para la contextualización de esta problemática se eligió la ciudad de Barcelona, que, por sus características, abarca un amplio abanico de condiciones consideradas fundamentales y, a posteriori, se seleccionó uno de sus barrios más saturados por el proceso de masificación turística, La Barceloneta, situada en el distrito central de Ciutat Vella.

Con la finalidad de obtener informaciones actuales sobre el escenario turístico del municipio y del barrio en cuestión, se consultaron periódicos y páginas Web, se entrevistó a tres representantes de asociaciones vecinales y se optó por participar en las actividades que estas entidades promovieron entre junio de 2016 y septiembre de 2017 y que están vinculadas a la temática de esta investigación.

Se analizan, por una parte, las iniciativas de las instituciones públicas dirigidas al fomento del turismo como actividad económica en expansión, y cuyo empeño está directamente relacionado con la magnitud del flujo barcelonés. Por otra, se presta atención a condicionantes claves en la formación de la percepción hacia el turista, tales como el grado de contacto y de frecuencia del residente con los lugares repletos de foráneos y la actitud de éstos respecto a los autóctonos e, igualmente el nivel de pérdida de la calidad de vida en función del desarrollo de la actividad. Dependiendo de cómo se articulan estos elementos entre sí y con la intensidad del flujo turístico, el grado de afectación puede ser mayor y, por ende, el nivel de rechazo también.

Se subrayan las consecuencias que la puesta en marcha del 'modelo Barcelona', ha tenido en la reconfiguración territorial y más específicamente en el modo de reproducción de lo cotidiano de los residentes del barrio marítimo de La Barceloneta, cuya proximidad al centro urbano y buena accesibilidad a sus playas le ha transformado en una de las principales áreas turísticas de Barcelona

Para esto se exponen las particularidades de un escenario en el que las demandas de los visitantes discrepan de las necesidades cotidianas de los residentes y, a continuación, se reflexiona sobre cómo este proceso ha estimulado la organización y las protestas vecinales. Éstas han exigido que se reglamenten tanto el uso del espacio público, como la transformación de las residencias habituales en viviendas de uso turístico (VUT), un proceso que ha expulsado del barrio un gran número de vecinos.

1 Según el Barómetro de la Organización Mundial de Turismo el número de turistas internacionales subió en 2015 el 4\% respecto a 2014 y en 2017 se incrementó un 7\% respecto a 2016, hasta el récord de 1.322 millones en todo el mundo. Se estima que este impulso se mantendrá en 2018. <http://media.unwto.org/es/press-release/2018-01-15/resultados-del-turismo-internacional-en-2017-los-mas-altos-en-siete-anos>. 
Estos, y otros temas correlativos son los que permean el presente debate, en el que, partiendo del ámbito barcelonés, se evalúan los impactos socio territoriales que el turismo de masas ha provocado en el barrio de La Barceloneta.

\section{EL ANÁLISIS DE LA RELACIÓN ENTRE LA POBLACIÓN RESIDENTE Y EL TURISTA}

El estudio de George Doxey sobre la teoría de la causalidad entre visitantes y residentes irritados publicado en 1975 fue pionero en este análisis y supuso una importante contribución al tema. En su propuesta fundada en un índice de irritabilidad, evalúa las interacciones y relaciones entre turistas y residentes a partir de una escala de cuatro etapas: euforia y placer en el contacto; apatía e indiferencia creciente con el aumento del número de turistas; irritación y preocupación o aborrecimiento con el aumento de los precios, delito o la transgresión de las normas culturales locales; y finalmente, el antagonismo y agresión abierta a los visitantes. Argumenta que, con el aumento del número de turistas, la comunidad que los hospeda, pasa de la fase de euforia, cuando los residentes poseen expectativas con relación al desarrollo de la actividad, para las fases de la apatía, irritación y antagonismo.

En el análisis realizado por Richard Butler sobre el ciclo que comprende la actividad turística, realizado en 1980, el autor resalta que es en la fase de la consolidación de la misma, debido al gran número de turistas e infraestructura creada para ellos en detrimento de la población local, que se acentúan los impactos sociales, principalmente en lo que se refiere al descontento entre los residentes.

Algunos informes como el Statewide Tourism Impact, realizado por el Departamento de Comercio y Desarrollo Económico de Hawai y publicado en 1989, ya revelaban que, pese a que el $80 \%$ de los residentes consideraban el contacto con el turista agradable, el $25 \%$ de los residentes opinaba que sus áreas de ocio habían sido "tomadas" por turistas y el 38\% mencionaba que el tráfico había empeorado (Pearce, 2002).

Fue lo que D. Weaver y L. Lawton (2001) constataron también en un estudio sobre la percepción de los residentes con referencia al turismo en Tamborine Mountain, franja urbana-rural australiana de Gold Coast. Este reveló que los residentes que 'apoyan' la actividad constituían solo un cuarto de la población. La mitad de sus habitantes, aunque reconociendo los beneficios económicos y resaltando los impactos sociales se consideran "neutros". Otra cuarta parte de los vecinos, al subrayar que el turismo como actividad genera únicamente empleos, se consideraban "oponentes" a la actividad. Los autores observaron igualmente que la reacción anti-turística se halla principalmente en los lugares con gran afluencia de foráneos.

A su vez, B. Archer y C. Cooper (2002) sostienen que los impactos socioculturales dependen del grado de intensidad del desarrollo turístico y afirman:

"Aunque de difícil medición, hay una relación entre la densidad del turismo y el crecimiento del resentimiento local contra él. El flujo de turistas en una región aumenta las densidades en que viven las personas y supera la capacidad de las instalaciones que ellos deben compartir con la población local. La superpoblación rebaja el valor de la experiencia de vacaciones y crea más tensión para la población residente" (p. 95) 
Archer y Cooper añaden que, en casos extremos, la población local se ve impedida de disfrutar de las áreas naturales de su propia región o país, y menciona el caso de la costa mediterránea, producido y reproducido en muchas otras áreas litorales del mundo, donde parte de la orla ha sido adquirida por hoteles para el uso exclusivo de sus huéspedes, lo que ocasiona a los residentes, dificultades para acceder a playas frecuentadas habitualmente. Un proceso que puede llevar a lo que los autores denominan de "efecto confrontación".

La tesis sobre la isla de Ibiza (España) elaborada por José Ramón Cardona (2012), resalta el alto porcentaje de ibicencos que perciben los efectos negativos del turismo de masas en la misma: la perdida de identidad y de las costumbres de los residentes, los conflictos socio culturales entre visitantes y autóctonos, la saturación de ciertos espacios naturales y la degradación medioambiental, el incremento de la inflación y de los precios de la vivienda, el aumento de los problemas de tráfico y de seguridad ciudadana.

Del mismo modo, en un estudio publicado en 2013, Manuel Ramón González Herrera y Mabel Font Aranda señalan los impactos del turismo sobre dos comunidades cubanas costeras, Cárdenas y Caibarién. Las conclusiones son que las actividades turísticas impactan en los sectores tradicionales (pesquería), desplazando a las personas y la fuerza de trabajo, provocando el aumento de las desigualdades sociales.

\section{3. ¡HACIA LA TURISTIFICACIÓN DE LA CIUDAD DE BARCELONA!}

Uno de los mayores legados de los Juegos Olímpicos de 1992, ha sido, sin duda, la consolidación de la ciudad de Barcelona como centro turístico. En 1989 se puso en marcha el primer Plan Estratégico, cuyo objetivo era el de planificar y ejecutar las obras de infraestructura para los Juegos Olímpicos. En él se incluyeron la abertura de grandes avenidas y la remodelación de barrios como el de Montjuic y de Poble Nou, éste último en su porción litoral que correspondió a la Vila Olímpica.

Se trata de un nuevo modelo defendido con énfasis después de los Juegos Olímpicos, durante y después del período calificado como "resaca post-olímpica" (19921997) en el que la desaceleración de las actividades económicas vinculadas al sector turístico se hizo notoria. Para revertir esta situación e impulsar una nueva estrategia que más tarde se conocería por city-marketing o city branding, se instituyó en 1993 un organismo municipal de promoción turística denominado Turisme de Barcelona, se puso en marcha el Segundo Plan Estratégico (1997-2006) y otras medidas que se siguieron a éste ${ }^{2}$.

Con el fin de crear un entorno favorable al crecimiento urbano y atractivo al capital, su ejecución, impulsó la institución de agencias de sociedades público-privada y atrajo numerosos inversores privados que actuaron decisivamente en la realización de megaproyectos urbanísticos y en la transformación de la morfología urbana barcelonesa. Asimismo, planteó un intenso programa de divulgación de la ciudad y de sus atributos, como ciudad gótica, ciudad modernista, ciudad de diseño y ciudad de compras, optimi-

2 Para más informaciones sobre este proceso, véase Horacio Capel, 2005, Miriam Zaar, 2017b, entre otros. 
zando su imagen internacional y atrayendo tanto el turismo vacacional como el turismo de negocios, de eventos culturales y deportivos.

Favorecidos por estas dinámicas políticas y económicas que estimularon las inversiones, los promotores inmobiliarios y sus operadores actuaron en un abanico de sectores que fueron mucho más allá de la hostelería, y se expandieron en las ramas de la restauración, cultura, deporte, entre otras, llevando a la consolidación de este modelo.

Vinculado a este proceso, la demanda hotelera no paró de crecer. El modelo que se venía desarrollando desde los Juegos Olímpicos y que fomentó un alza del $26 \%$ en el número de alojamientos turísticos entre 1990 y 1995, tuvo otro pico importante en la preparación y realización del Fórum de las Culturas, promoviendo un esponjamiento urbanístico y turístico hacia los espacios no urbanizados en las zonas periféricas, lo que impulsó un nuevo incremento en el número de establecimientos de alojamiento (30\%) y en el número de plazas (36\%) (Zaar, 2017b:7-9).

Siguiendo esta coyuntura, en la que el paradigma neoliberal permeó el proceso de reestructuración y renovación urbana, promoviendo la gentrificación y la suburbanización de los territorios metropolitanos, se aprobó en 2010, el Plan Estratégico de Turismo de la Ciudad de Barcelona 2010-2015, cuyos objetivos mostraron una clara intención de propulsar el desarrollo de las actividades turísticas mediante la financiación de éstas, a través de cambios urbanísticos en diversos barrios y de la incorporación de nuevas infraestructuras, como la nueva terminal del Aeropuerto de Barcelona y varios terminales portuarias internacionales (Zaar, 2017b:5-15).

Se trata de mecanismos, que promovieron notables cambios urbanos, hasta el punto de que algunos geógrafos los consideran como dispositivos para la implementación de un "contra modelo" (Capel, 2007; Borja, 2005) que fomentó la promoción de la marca Barcelona a través de un gran número de eventos internacionales lo que ha otorgado a esta ciudad un puesto destacado entre las ciudades más visitadas del mundo.

Como resultado de esta dinámica, el número de turistas que se hospedó en hoteles barceloneses entre 2005 y 2017 pasó de 4,2 millones anuales a más de 7,5 millones (7.678.043), en un proceso en el que desde 2011 el número de extranjeros ha ido reemplazando al turista nacional, hasta el punto de que en los años de 2016 y 2017 éste último representó solamente el 20\% del total de visitantes (Ayuntamiento de Barcelona, 2018b).

El estudio Global Destination Cities Index elaborado por MasterCard en 2015 señaló que Barcelona era la tercera urbe del continente europeo, donde los viajeros realizaban mayores gastos. Solo quedaba por detrás de Londres y París, y se hallaba en la $12^{a}$ posición en volumen de viajeros y la sexta ciudad con más ingresos turísticos de todo el mundo. Una posición europea y mundial que se ha mantenido en los años siguientes.

En su promoción turística y cultural han tenido un rol fundamental las rutas de arquitectura gótica y modernista. La primera, situada en las zonas céntricas, y la segunda, esparcida en el Ensanche y zonas adyacentes, objetivo de valoración por parte de una muchedumbre de turistas. Un fenómeno que forma largas "mareas humanas" en el Barrio Gótico, las Ramblas, Mercado de la Boqueria, Paseo de Gracia (Casa Milà, Casa Batlló), en el entorno de la Sagrada Familia, y que se expande hacia las calles y barrios que conducen a otros enclaves emblemáticos, como el Park Güell. Además, en áreas poco 
urbanizadas, y por lo tanto con amplios espacios en que el suelo estaba a la espera de una mayor revaloración, se han proyectado obras singulares con un objetivo principal: propiciar oportunidades para la reproducción del capital inmobiliario. Este es el ejemplo del Fórum de las Culturas (2004), cuyo entorno se reestructuró con la construcción de hoteles, amplias avenidas y edificios comerciales y residenciales.

Se trata de un proyecto urbano en el que para que se cumplan las expectativas de los turistas, con relación a sus espacios simbólicos, la ciudad de Barcelona "se ha convertido un parque temático donde se trata a los ciudadanos como turistas de los que solo se espera que admiren, consuman y callen" (Capel, 2007).

En este escenario, el proceso de gentrificación, como un conjunto de operaciones urbanísticas sobre áreas consolidadas que, por su posición geográfica, morfológica o atributo paisajístico, se tornan atractivas, "avanza en una tensa afinidad con el turismo" y "se ha transformado en el extremo residencial dominante de un proyecto mucho más grande: la reconstrucción de clase del paisaje de los centros urbanos" (Smith, 2012:85-88).

Con el propósito de estimular la apropiación y mercantilización del espacio urbano se crean mecanismos basados tanto en la explotación y reinvención de espacios ya turistificados, como en la inclusión de zonas que se encuentran al margen de esta dinámica y que por esto mantienen su estructura social y cultural. Estas últimas, por su singularidad, son aquellas donde los agentes inmobiliarios pueden lograr mayores tasas de ganancias.

Este proceso ocurre a través de la entrada de capitales multinacionales y fondos de inversión en compraventa y gestión hotelera vinculados a las Sociedades Anónimas Cotizadas de Inversión Inmobiliaria (SOCIMIS), que demandan solares y edificios para convertirlos en hoteles, hostales, albergues de juventud, residencias colectivas de alojamiento temporal o viviendas de uso turístico (VUT), en el que tanto la vivienda cómo los espacios públicos se transforman en mercancía. Datos del PEUAT señalan que a finales de 2016 casi un $40 \%$ del número de plazas de los alojamientos turísticos disponibles en la ciudad de Barcelona (59.014 de un total de 148.482) estaban situados en viviendas residenciales (Zaar, 2017b:17).

\section{EL BARRIO DE LA BARCELONETA: ANÁLISIS DE UNA DIFÍCIL RELA- CIÓN ENTRE EL RESIDENTE Y EL TURISTA}

El distrito de Ciutat Vella es por su interés histórico y proximidad al mar y a las playas, donde están situados los barrios que reciben más turistas: La Barceloneta, el Barrio Gótico, La Ribera y El Raval (figura 1).

El turismo masivo y todos los procesos que se transforman en causa y efecto de esta actividad económica han repercutido en el modo de vida de los cien mil ciudadanos barceloneses $^{3}$ que residen y trabajan en el distrito de Ciutat Vella y que se apropian colectivamente de sus espacios públicos. Diversas fuentes estiman que en este distrito existen unas 17 mil plazas hoteleras y cerca de 600 viviendas de uso turístico legales y varios miles ilegales ${ }^{4}$.

3 Ayuntamiento de Barcelona, datos de 2015-2016 (2016c) <http://www.bcn.cat/estadistica/castella/ dades/anuari/cap02/C020102.htm>.

4 Informes Anuales Turismo en Barcelona 2014, Barcelona Turisme y PEUAT, 2017, estimativas realizadas por Asociaciones Vecinales, respectivamente. 


\section{Figura 1 \\ LOCALIZACIÓN DEL DISTRITO DE CIUTAT VELLA Y DEL BARRIO LA BARCELONETA (BARCELONA)}

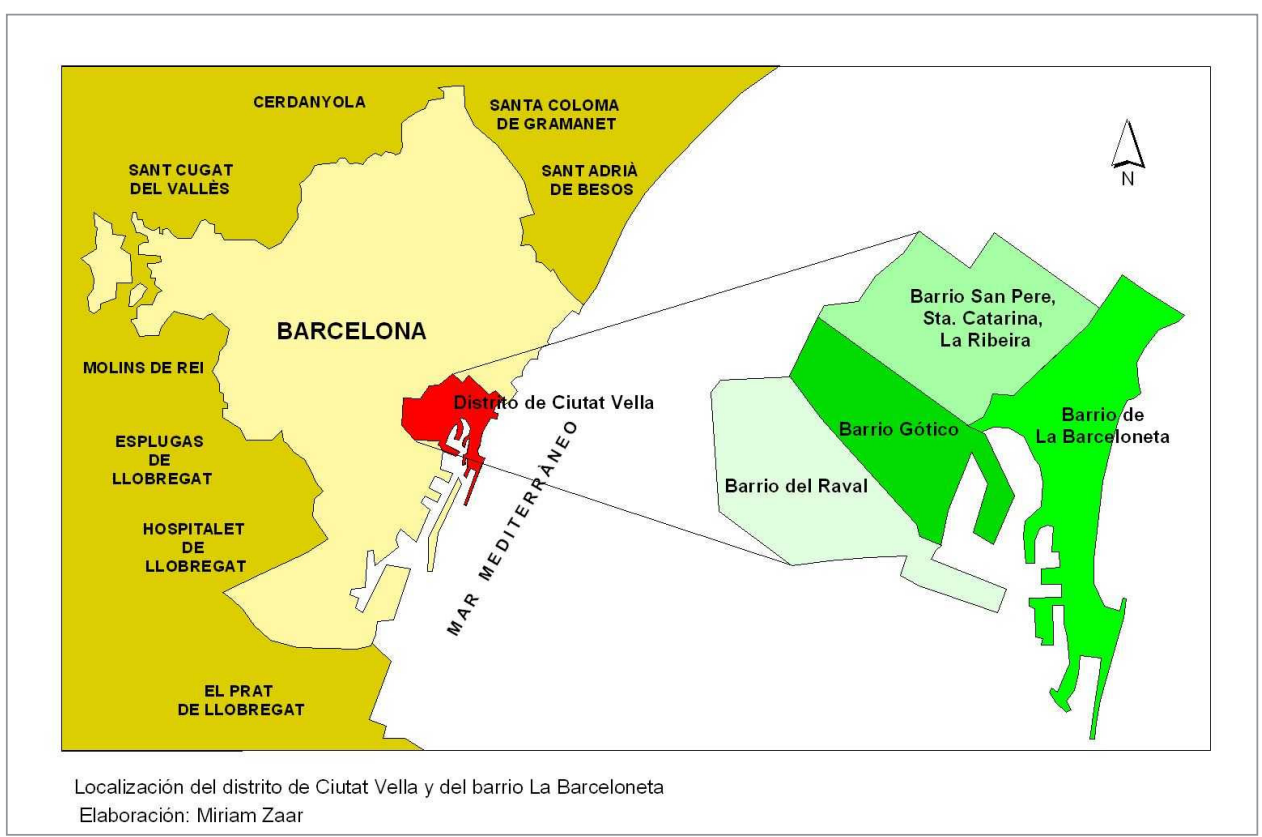

Fuente: Elaboración Miriam Zaar.

Aunque se podría afirmar en principio que la percepción del residente hacia el turismo de masas es similar en los cuatro barrios que comprenden el distrito de Ciutat Vella, este análisis se centra en uno de ellos, La Barceloneta. Esta opción se debe a su contexto histórico, su remodelación urbanística y portuaria ocurrida a partir de las Olimpíadas de 1992, la reciente construcción del hotel de lujo W Hotels en un lugar costero y estratégico del barrio y la previsión de que, en sus proximidades, se edifique el futuro museo Hermitage Barcelona.

Éstos constituyen nuevos elementos que, al integrarse al territorio, incrementan la presión turística e inmobiliaria sobre el barrio de viviendas construidas durante los siglos XVIII y XIX e intensifican los problemas asociados a la especulación inmobiliaria y la expulsión vecinal, acompañados por un evidente conflicto residente-visitante, lo que ha reavivado la tradición reivindicativa del barrio, como se analiza en los próximos apartados.

\subsection{El barrio de La Barceloneta y su contexto histórico}

La configuración urbana de La Barceloneta pasó por varias etapas. Su inicio nos remite al siglo XVIII, cuando se elaboró un proyecto de construcción de viviendas para albergar la clase obrera que vivía en la porción oriental del Barrio de La Ribera y había sido desalojada para la construcción de la fortaleza militar de la Ciudadela. 
Inicialmente sus edificios albergaban mayoritariamente funciones públicas y militares, comerciales (ventas, almacenes, instalaciones portuarias) y viviendas que albergaron, además de los remanentes del programa de desalojo del barrio La Ribera, pescadores y sobre todo trabajadores portuarios, cuya demanda había aumentado debido a la ampliación del puerto y al incremento de las actividades mercantiles derivada del mismo (Tatjer, 1973 y 2015).

Durante el siglo XIX parte de estas actividades económicas fueron, progresivamente, cediendo lugar a otras de carácter industrial vinculadas a la metalurgia y a la mecánica (astilleros y talleres) ${ }^{5}$ y de servicios (instalaciones ferroviarias). También aparecieron otras asociadas al ocio y esparcimiento, como la Plaza de Toros instalada en 1836 y las instalaciones para baños en la zona de playa que funcionaron desde el inicio siglo XIX hasta 1971 (Tatjer, 2012). Además, la oferta laboral en las industrias incrementó la llegada masiva de inmigrantes a la ciudad de Barcelona y en consecuencia a la Barceloneta, lo que promovió una mayor demanda de viviendas. Esta se resolvió a través del crecimiento en altura de los edificios de viviendas desde dos hasta las cinco o seis plantas actuales y de la división de las viviendas ${ }^{6}$.

En el siglo XX, proyectos urbanísticos vinculados a la construcción del Paseo Marítimo (primer tramo en 1957) y su enlace con el Paseo Nacional, así como el Plan Director del Área Metropolitana de Barcelona (1966), el Plan Ribera (1965-1971) y el Proyecto de modificación del Plan Comarcal de Ordenación Urbana de Barcelona afectando al Sector Marítimo Oriental (1970), estimularon importantes modificaciones en este barrio. En lo que se refiere al Plan Parcial de Ordenación Urbana de la Ribera de Barcelona (Plan de la Ribera,1965-1971) que contemplaba la reordenación de la fachada marítima iniciado desde la Barceloneta, éste promovió la recalificación de los terrenos hasta entonces industriales, generando una importante plusvalía para empresas como Renfe, Catalana de Gas, La Maquinista, entre otras, cuyas extensas superficies se transformaron en equipamientos turísticos o áreas residenciales de alto nivel (Tatjer, 1973).

En la década de 1970 entró en vigor el Plan General Metropolitano (PGM) y a partir de este se planteó la elaboración del Plan Especial de Reforma Interior (PERI), procesos a los que las organizaciones vecinales, investigadores y activistas se opusieron debido a la nula participación ciudadana. Frente a ello, e impulsado por los debates, se elaboró el Estudio Previo a la Remodelación de La Barceloneta, en el que se reivindicaba: a rehabilitación de las viviendas situadas en la trama histórica del barrio, la reconversión de las zonas industriales obsoletas en equipamientos, espacios públicos y nuevas viviendas, además se reclamaba la supresión de las barreras físicas como las vías ferroviarias que aislaban el barrio de la ciudad de Barcelona (Vilanova, 2012). El hecho de que estas

5 Según Ildefonso Cerdá, en 1858 solamente los talleres de maquinaría ocupaban cerca del $10 \%$ de la superficie del barrio (Mercedes Tatjer, 1973, p. 55).

6 Según Mercedes Tatjer, estas viviendas, también son denominadas de "cuartos de casa", por constituirse en la cuarta parte de la vivienda original del siglo XVIII $\left(140 \mathrm{~m}^{2}\right)$, como consecuencia de una primera partición en dos (mitja casa) en la segunda mitad del siglo XIX y a posteriori (siglo XIX), en una nueva división en la que cada una de estas medias casas se transformó en dos viviendas con aproximadamente $35 \mathrm{~m}^{2}$. Situadas inicialmente en una primera planta, en 1838 se concedieron permisos para la edificación de una segunda planta, en 1872 se otorgaron licencias para la construcción de las tercera y cuarta plantas y, en 1930, ya se observaban edificios con siete plantas (Mercedes Tatjer, 1973 y entrevistas). 
circunstancias se produjesen en el período de la transición democrática (1975-1978) hizo viable que, finalmente, el Ayuntamiento de Barcelona acordara en que algunos de los que concibieron este Estudio previo participasen en la redacción del Plan Especial de Reforma Interior (PERI).

Desde finales de la década de 1980, concurrieron a la actual configuración urbanística de barrio, las reformas llevadas a cabo para los Juegos Olímpicos de Barcelona de 1992, con la retirada de las estructuras portuarias, de las vías ferroviarias y el saneamiento de la playa, se abrieron espacios nuevos como el Paseo Marítimo y se construyeron hoteles y otros equipamientos turísticos.

A pesar de ello, a comienzos del siglo XXI el barrio de La Barceloneta todavía conserva algunas singularidades de los siglos XVIII y XIX, como el plan inicial, con sus calles largas y estrechas interrumpidas por algunas plazas y sus manzanas rectangulares paralelas al puerto en las que se ubican edificios de viviendas que exteriormente mantienen sus características originales, aunque su "apertura al mar" se está transformando en nuevas oportunidades para diferentes agentes turísticos. Según explica una residente, miembro activo de la Asociación vecinal L'Óstia, "ellos vieron La Barceloneta como la gallina de huevos de oro, con playa y muy cerca de la Vila Olímpica, lo que generó una especulación pura y dura del barrio" (Entrevista, agosto de 2016).

En esta dirección, se vislumbra un proceso de gentrificación, pautado por la construcción de hoteles y el incremento de plazas de modalidades de alojamientos turísticos asociados al cambio de uso de viviendas residenciales y a la ampliación de áreas de ocio. Todo ello con el propósito de aumentar el número de foráneos y consolidar el turismo de masas, una lógica que, en la última década ha sido fomentada por los paquetes turísticos asociados a los vuelos low cost y a plataformas como Airbnb y Homeaway, y que ha generado un proceso especulativo que ha inducido a una fragmentación del tejido social y ha llevado a la pérdida de parte de su población 7 . La subida de los precios de venta y de alquiler de los inmuebles ${ }^{8}$, el reemplazo de parte de los vecinos llevado a efecto a través de la adquisición de viviendas y edificios por parte de grupos inversores nacionales y extranjeros, incitando, y a veces forzando la salida de residentes cuyas bajas rentas no permiten pagar alquileres más altos o participar de proyectos de rehabilitación de sus fincas, son algunas de las consecuencias.

Otros vuelcos sociales del barrio están vinculados a un importante cambio en la tipología de sus visitantes, ya que los visitantes tradicionales (familias generalmente procedentes de la ciudad o de la provincia de Barcelona), que en fines de semana o en períodos de vacaciones, paseaban por sus calles y saboreaban sus vinos y platos típicos en los restaurantes han sido reemplazados por una muchedumbre de turistas con intereses dispares e incluso discordantes de la población residente, lo que ha generado confitos y disputas por la utilización del espacio público en varios puntos del barrio.

7 Ayuntamiento de Barcelona. Ponencia del Pla de Ordenación Urbana. Explotación del Padrón de 1965, apud Mercedes Tatjer, 1973; Ayuntamiento de Barcelona. La población de La Barceloneta ha presentado una significativa disminución en los últimos años <http://www.bcn.cat/estadistica/castella/documents/barris/index.htm>.

8 El distrito de Ciutat Vella, ha registrado, en los últimos años precios por encima de la media de la ciudad de Barcelona (Idealista.com). 
Esta coyuntura, hizo que el barrio de La Barceloneta fuera perdiendo, paulatinamente, su carácter de barrio residencial de pescadores y trabajadores del puerto ${ }^{9}$, para convertirse en una de las zonas más atractivas para el turismo de masas, principalmente por sus bajos precios $^{10}$ y su ubicación, entre la playa y el centro de la ciudad.

Como consecuencia de la implantación de este modelo turístico, han surgido conflictos tanto entre residentes y turistas, como entre residentes y agentes turísticos, que se analizan a continuación desde varias perspectivas.

\subsection{La Barceloneta como locus de disputa por el uso del espacio público}

En el proceso de turistificación de las ciudades que suele ir acompañado del proceso de gentrificación, el espacio público como valor de uso, así como cualquier otro producto, se transforma en valor de intercambio, esto es, en mercancía. En el barrio de La Barceloneta, las calles, las plazas, las playas, las aceras cercanas a los restaurantes, bares y otros negocios, hasta poco más de una década frecuentados por el vecindario o barceloneses procedentes de otros barrios, han pasado por un proceso de apropiación y privatización de modo que, en muchas ocasiones, para utilizarlo se hace necesario el consumo.

Esto es así porque los servicios destinados al turismo de masas, no se apropian solamente de un espacio concreto, como las aceras ocupadas por terrazas con jardineras y parasoles que en muchos casos sustituyen los bancos públicos, sino también de sus alrededores y de las vías que articulan este espacio con otros espacios de consumo, sean restaurantes, bares o el propio alojamiento, comprometiendo el uso de este mismo espacio por los residentes.

En el barrio de La Barceloneta se observa este hecho, nada más salir de la estación de metro homónima. Además, cualquier ciudadano que se disponga a visitar el barrio entre marzo y octubre se dará cuenta de que, en medio a la multitud de personas que circulan por las vías del barrio que enlazan la estación del metro Barceloneta y la playa, es difícil encontrar un vecino, ni en horario vespertino, en que tradicionalmente se sale a la calle para "tomar el fresco".

Un escenario que ha ocasionado importantes cambios en las principales vías del barrio. En el Paseo Juan de Borbón (antiguo Paseo Nacional), los pocos restaurantes que había fueron sustituidos por otros enfocados hacia la demanda turística que, ocupan parte de las aceras con sus terrazas y plafones publicitarios (figuras 2).

En el mismo paseo, en su acera opuesta, centenares de manteros ocupan las dos franjas laterales de la misma, (figuras 3 y 4) dificultando y a veces impidiendo la circulación vecinal y también de los visitantes.

9 Cómo constató Mercedes Tatjer en el inicio de la década de 1970, el 27,6\% de los obreros portuarios y el 57,4\% de los pescadores artesanales de Barcelona vivían en La Barceloneta.

10 Que, según entrevistas realizadas, se aproximan a los 400 o $500 €$ por semana, en un apartamento que puede ser compartido por 4 o 5 personas. 


\section{Figura 2 \\ APROPIACIÓN DEL PASEO JUAN DE BORBÓN POR RESTAURANTES}

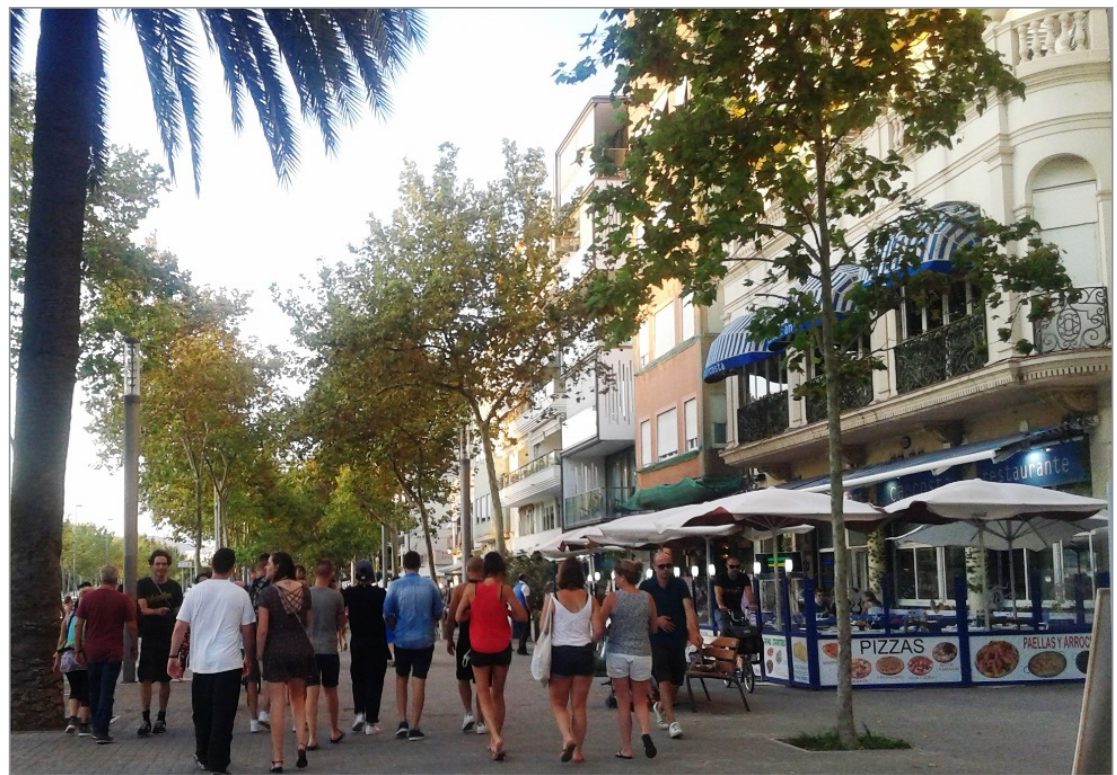

Foto: Miriam Zaar, junio 2018.

Figuras 3 y 4

OCUPACIÓN DEL PASEO JUAN DE BORBÓN POR MANTEROS

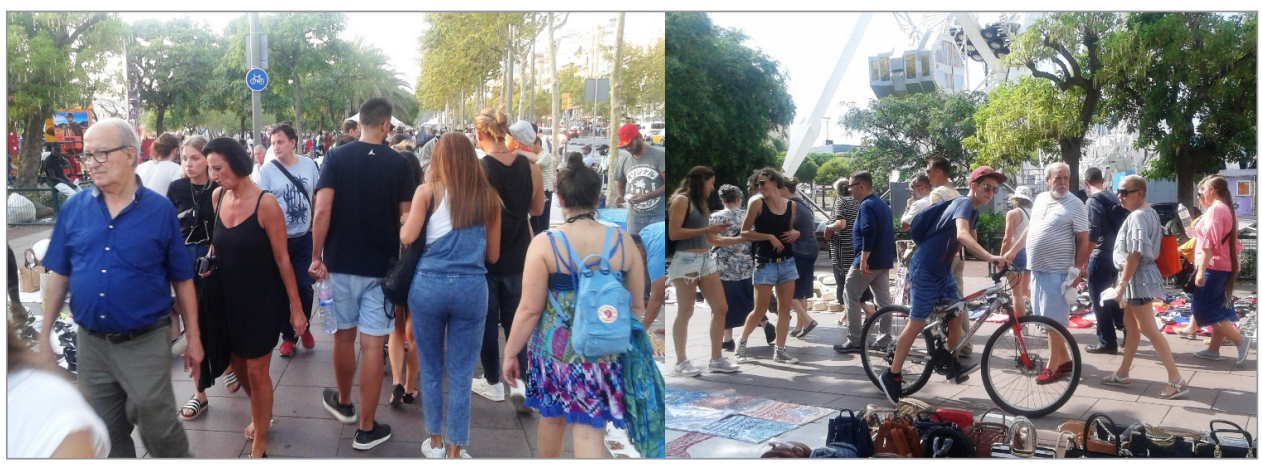

Foto: Miriam Zaar, agosto y septiembre 2018, respectivamente.

Este proceso ocurre tanto en lugares con mayor afluencia de visitantes (Paseo Juan de Borbón y Paseo Marítimo), cómo en lugares más recónditos en los que se incluyen las plazas de La Barceloneta y de La Repla con su mercado. Éstos albergan restaurantes tradicionales y bares que siguen la misma lógica, expropiado amplios espacios del cotidiano 
barcelonés, a menos que se pague para utilizarlo (figura 3 ) $^{11}$. Sus amplias terrazas en las que sirven platos que atraen a los foráneos e incluso anteponen la atención a estos a la de los residentes, inhiben o impiden a los mayores reunirse y a los niños jugar y consecuentemente, restringen la socialización entre sus vecinos (figuras 5 y 6 ).

\section{Figuras 5 y 6 \\ APROPIACIÓN DEL ESPACIO PÚBLICO POR RESTAURANTES EN EL PASEO MARÍTIMO Y LA PAZA DE LA BARCELONETA}

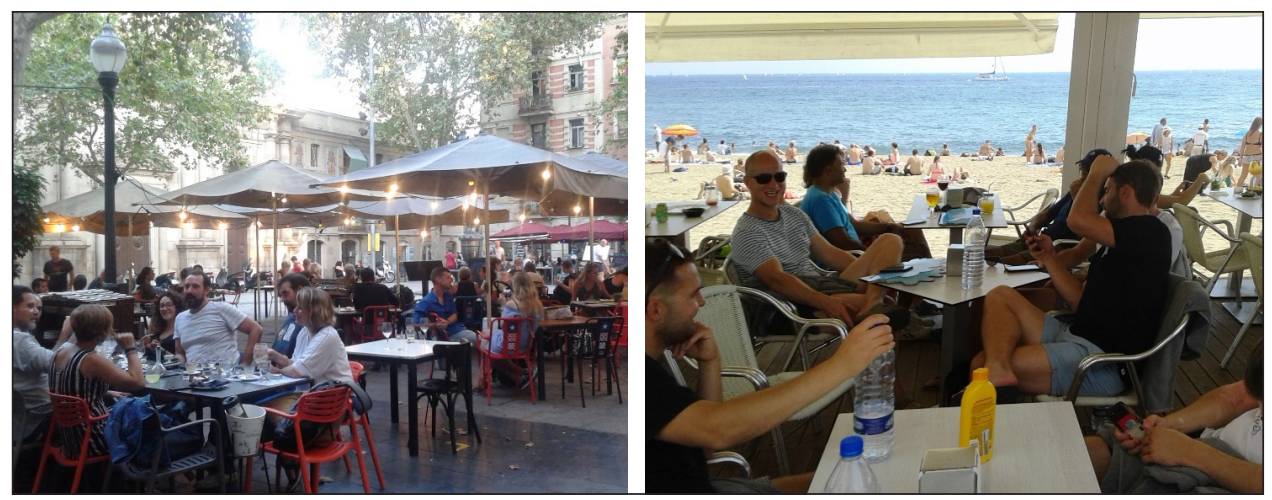

Foto: Manuel-Blas García, mayo y junio 2018.

El proceso de privatización del espacio público ocurre igualmente en la playa en la que las sombrillas, hamacas y el suelo en el que están situadas se transforman en objeto de mercantilización, lo que desde hace años ha sido motivo de enfrentamiento entre vecinos y agentes turísticos.

Asimismo, y asociados al gran contingente de turistas, la proliferación de vehículos de alquiler de dos y tres ruedas, como bici-taxis o rickshaws, patinetes, segways, bicis, etc. entorpecen el paso de vecinos y demás transeúntes (figuras 7 y 8 ).

Se trata de un proceso, que relega la autenticidad y las señas de identidad del barrio frente a la homogeneidad de los espacios, e impide, incluso niega su condición de categoría política que organiza la vida social y colectiva por excelencia (Delgado y Malet 2007).

Incorporados en esta dinámica están los negocios que sufrieron importantes cambios. Unos substituyendo gran parte de sus productos tradicionales por los vinculados a la demanda de los visitantes (figura 9). Otros negocios fueron reemplazados por una amplia oferta de comida rápida, bebidas alcohólicas y souvenires, que funcionan las 24 horas y que están a margen de las necesidades vecinales y ocupan aceras y plazas (Entrevista, agosto de 2016).

11 Según datos del Ayuntamiento de Barcelona, 2018b, las actividades económicas vinculadas al turismo y hostelería ha representado en los últimos años los siguientes porcentajes: 21,1\% (2010), 35,9\% (2011), 28,8\% (2012), 27,3\% (2013), 26,2\% (2014), 26,4\% (2015), 26,2\% (2016) y 25,6 (2017). <http://www.bcn.cat/estadistica/castella/documents/barris/03_CV_Barceloneta_2018.pdf> 
Figuras 7 y 8

ESTRANGULAMIENTO DEL ESPACIO PÚBLICO POR VEHÍCULOS DE DOS Y TRES RUEDAS DE ALQUILER

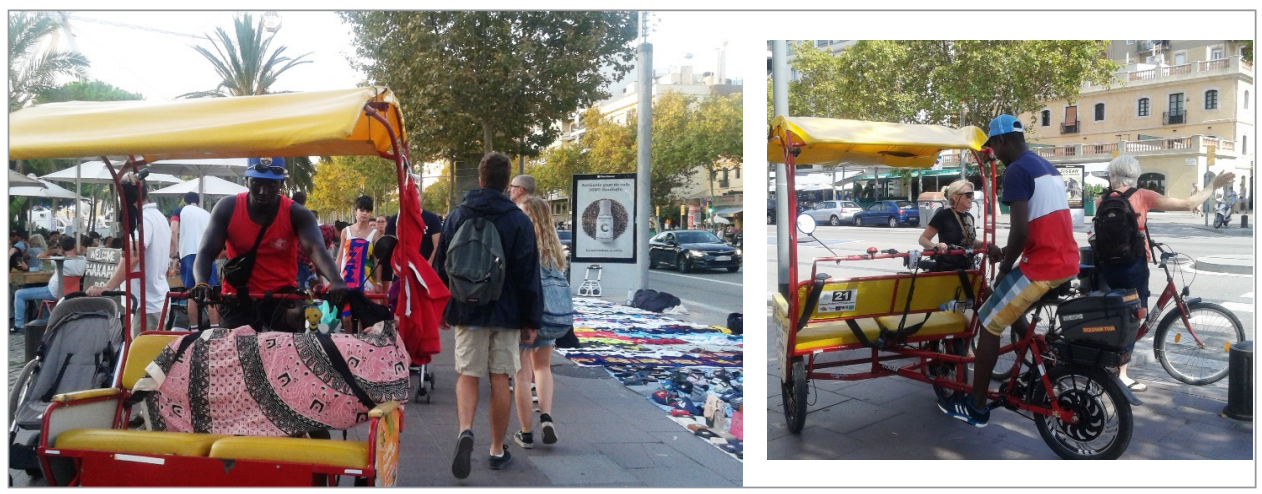

Foto: Manuel-Blas García, junio y julio 2018.

Figura 9

QUIOSCO TRANSFORMADO EN TIENDA DE SOUVENIRS Y PRODUCTOS DE PLAYA

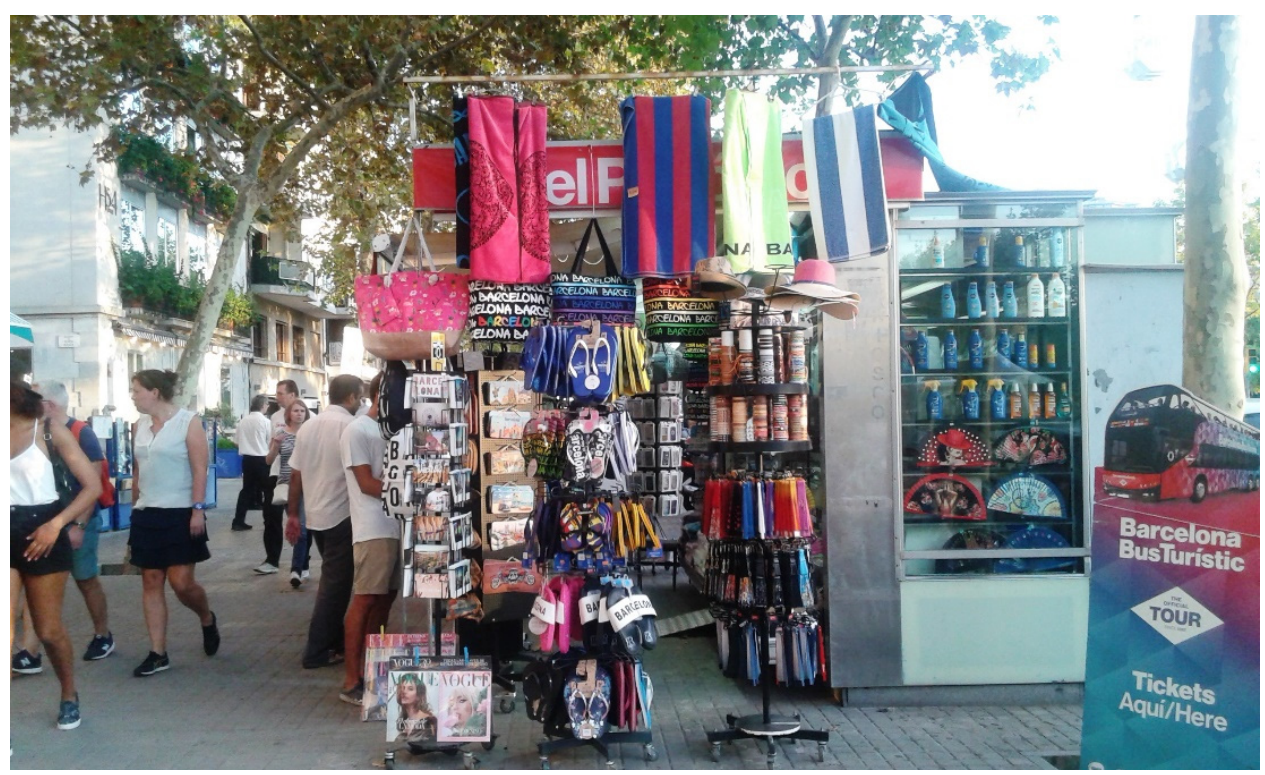

Foto: Manuel-Blas García, septiembre 2018. 
La materialización de estas acciones no solo produce la mutación del espacio público y conlleva a la construcción de íconos de homogeneización, sino que también obstaculiza la reproducción del cotidiano vecinal y desterritorializa a los residentes.

\subsection{Gentrificación: la expulsión vecinal y la difícil coexistencia con los huéspedes de las viviendas de uso turístico}

El proceso de turistificación de los barrios céntricos suele venir acompañado de la gentrificación como un "fenómeno de reconquista de las áreas centrales y de las zonas consolidadas de las ciudades por el poder económico, particularmente cuando se trata de la apropiación de esos espacios por parte de los agentes inmobiliarios privados y sus operaciones de capitalización de renta del suelo" (Casgrain y Janoschka, 2013, p. 20).

En España han coadyuvado a esta dinámica, además de la entrada de capitales multinacionales y fondos de inversión en negocio de compraventa y gestión hotelera, la aprobación de la Nueva Ley de Arrendamientos Urbanos (LAU) reformada en 2015, que adoptó medidas de flexibilización en el mercado de alquiler de viviendas, desvinculando de la subida del IPC el acuerdo entre propietario e inquilino sobre los ajustes de la renta y reduciendo los contractos de alquiler de cinco a tres años de duración y sus prórrogas de tres años a uno, lo que ha fomentado el precio de la vivienda de compra y los precios del alquiler.

En el barrio de La Barceloneta, aunque la práctica de oferta de alojamientos extra hotelero, o sea, el alquiler de las denominadas viviendas de uso turístico o pisos turísticos se remonta al inicio de los años 2000, el debate sobre la necesidad de establecer una normativa se ha incrementado desde 2011. Este año, además de las 72 viviendas de uso turístico legales, se abrió, tras la denuncia de las asociaciones vecinales, expediente a otras 113 que no poseían permiso para ejercer la actividad. Tratase de un número muy por debajo de los centenares de viviendas de uso turístico ilegales que los residentes afectados aseguraban existir en el barrio. En agosto de 2014, solamente la Airbnb ofertaba en La Barceloneta, 477 viviendas de uso turístico, siete veces más que las 72 legalizadas. En julio de 2015, el número de viviendas cuyo cambio de uso había sido protagonizado por inversores y estaban anunciadas en Airbnb era de 212, equivaliendo a un 5,7\% del total de viviendas destinadas al alquiler (Ayuntamiento de Barcelona, 2016a).

Esta dinámica, en la que "el alquiler de viviendas para uso turístico se configura como un mercado de negocio y plusvalías que atrae a inversores y especuladores" (Blanco et $a l, 2017: 1518)$, interviene en lo cotidiano de los vecinos del barrio de La Barceloneta, en dos circunstancias diferentes, aunque estrechamente vinculadas.

Una, a través del mobbing inmobiliario en el que grupos inversores adquirieren edificios enteros y aprovechan algunas lagunas de la Ley de Arrendamientos Urbanos (LAU) para agilizar el proceso de desocupación de las viviendas de alquiler y su transformación en viviendas de uso turístico. Entre las estrategias utilizadas están la coacción económica y la intimidación a los inquilinos.

Otro contexto se refiere a la dinámica que rige la coexistencia entre las viviendas residenciales y las viviendas de uso turístico. Los excesos de los grupos de turistas, derivados de actitudes incívicas y ruidos ocasionados en estas últimas y/o en sus áreas comunes han generado una relación conflictiva en muchas comunidades vecinales y han provocado una 
actitud de contrariedad, y en casos concretos, incluso de rechazo hacia a los foráneos ${ }^{12}$. Sobre esta problemática se ha manifestado así una vecina de La Barceloneta: "Esto es un barrio trabajador. No es un barrio turístico. La gente vive, trabaja... los que trabajan en el puerto se levantan a las cinco de la mañana... o sea, que terminas histérica cuando noche tras noche no puedes descansar" (Zaar, 2017b:17).

Pese a que se trata de circunstancias diferentes, en ambas situaciones se pone de manifiesto una desconsideración hacia los vecinos de 'toda la vida'. A los desplazados, los procesos de especulación inmobiliaria los llevan a la pérdida de su vivienda y de sus relaciones sociales, sea por el desplazamiento forzoso o por la exclusión social, causándoles daños irreparables (Zaar 2017b:17-18).

A los que se quedan, se les substrae, por un lado, su derecho al descanso, ya que muchos foráneos les despiertan de madrugada debido al inmenso ruido que hacen, o cuando les llaman para abrir la puerta de la calle. Ante esta práctica habitual, una vecina explica cómo reaccionó cuando a las cinco de la mañana su interfono sonó: "estaba tan harta de que llamaran por la noche que les tiré un cubo de agua" (El País, 21/8/2014).

Por otro, se ven privados de suplir sus necesidades básicas cotidianas vinculadas, por ejemplo, a la compra de alimentos, ya que el comercio tradicional y de proximidad ha sido reemplazado por franquicias de restaurantes, bares, comida rápida o la venta de recuerdos, todos dirigidos hacia los visitantes (Zaar, 2017b:18).

Se trata de un escenario, en el que se ven afectados hasta un $80 \%$ de los barceloneses, entre los que se encuentran tanto los que poseen viviendas de uso turístico en su edificio, como los que no la poseen (Ayuntamiento de Barcelona, 2017). Al mismo tiempo que desplaza los autóctonos remplazándolos por una población turística flotante, compromete la calidad de vida de los que permanecen, conllevando a alteraciones significativas en el tejido social del barrio.

Constituye en lo que David Harvey denomina "acumulación por desposesión", o sea un proceso el que "el turismo desposee a los residentes de su género de vida histórico con la finalidad de acumular experiencias nuevas para su propia cotidianidad" (Hiernaux, González, 2014, p. 65) y que puede acarrear efectos nefastos para las ciudades y sus habitantes, como explica el arquitecto José María Montaner,

"Se genera, en definitiva, el lento efecto de ir expulsando a la población local y se potencia el alza de los precios de los pisos - susceptibles de entrar en el negocio turístico- y de los locales, que en los ejes más transitados dejan de ser de proximidad para ser de ocio y consumo turístico".

"Como la inmobiliaria, esta burbuja hotelera da beneficios a corto plazo a unos pocos, no aporta nada positivo a nuestra sociedad, ni empleo estable ni formación, no repercute en la mejora del metabolismo urbano ni en la calidad de vida de los habitantes, solo deja la huella de barrios forzados a transformarse". (El País, 10/04/2014).

12 En el informe Percepció del Turisme a Barcelona realizado en el año de 2016, el 15,3\% de los encuestados afirmaron existir viviendas de uso turístico en su edificio. Entre estos, un 50,8\% afirmaron que éstas causan entre mucha y bastante molestias, aunque en el distrito de Gracia, este porcentaje alcanzó al 58,3\% y en el barrio de La Barceloneta el 66,9\% (Ayuntamiento de Barcelona, 2016b). 
Nos referimos a las consecuencias que han llevado a una fuerte reacción de los barceloneses, organizados en movimientos vecinales y demás plataformas sociales, como se analiza a continuación.

\section{LA REIVINDICACIÓN VECINAL Y APROBACIÓN DEL PEUAT, AVANCES Y RETOS}

Ante este proceso, en el que se apuesta por lo que Harvey (2013) denomina de "urbanización del capital" se ha producido una reconfiguración socioeconómica y territorial de la ciudad de Barcelona y consecuentemente del barrio de La Barceloneta, por la que el turismo se ha transformado en uno de los mayores problemas de los barceloneses, y los movimientos sociales enfrentados a este problema han ganado fuerza.

En los Barómetros de Barcelona, publicados semestralmente por el Ayuntamiento, en los que se pregunta por el problema más grave de la ciudad, la preocupación con el turismo ha crecido constantemente: ha pasado de representar el $0,8 \%$ en diciembre de 2011, el $3,1 \%$ en diciembre de 2013 , el 4,5\% en 2014 y el 5,3\% en junio de 2015, para ascender a un $11 \%$ en diciembre de 2016 y a un $19 \%$ en junio de 2017 . Un importante incremento, ya que casi una quinta parte de los barceloneses ha mencionado la masificación turística que sufre la ciudad, como el principal problema, un porcentaje mayor que el paro $(12,4 \%)$ u otros problemas sociales (Zaar, 2017b:18).

\section{Figura 10 \\ PERCEPCIÓN DEL TURISMO POR LOS BARCELONESES}
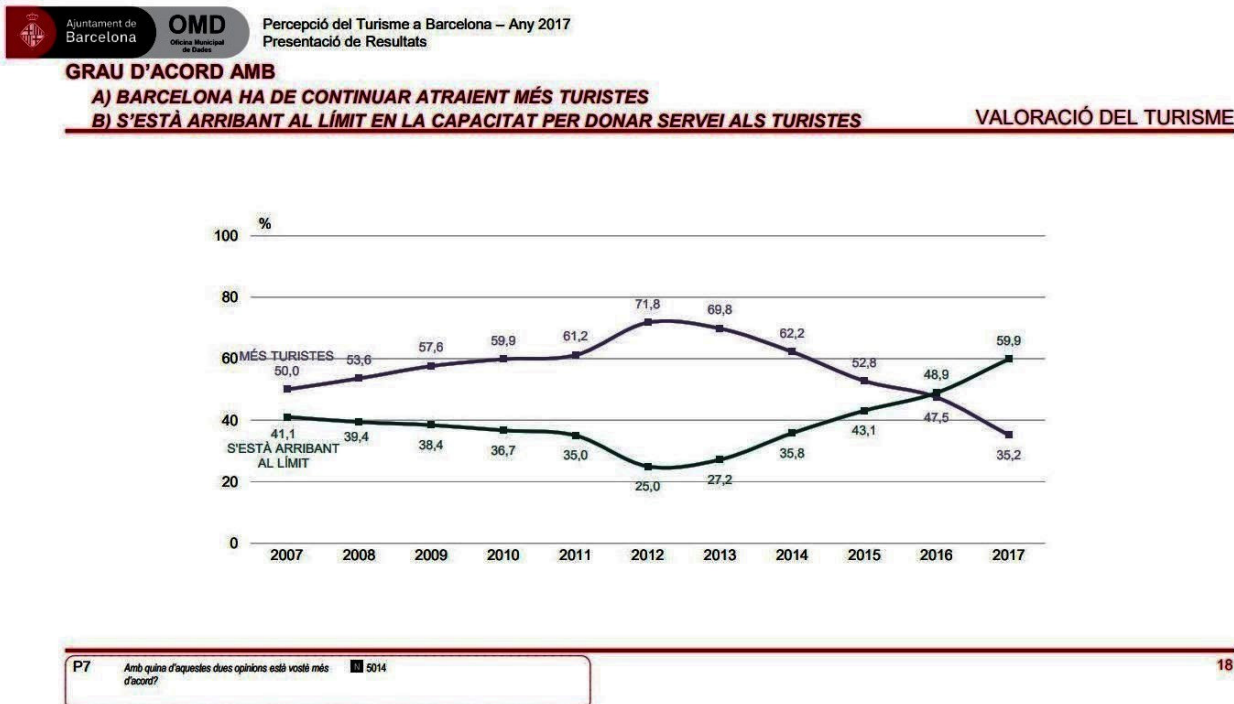

Fuente: <https://ajuntament.barcelona.cat/turisme/sites/default/files/percepcio_del_turisme_2017_informe_0.pdf> 
Asimismo, el estudio de Percepción del Turismo en Barcelona señala que el porcentaje de barceloneses que afirma que la ciudad de Barcelona debe continuar atrayendo más turistas ha descendido cerca del 50\% en los últimos años: de un 69,8\% (2013) a un 62,2\% (2014), un 52,8\% (2015), un 48,9\% (2016) y a un 35,2\% en 2017. Del mismo modo, el porcentaje de los ciudadanos que piensan que Barcelona está alcanzando su límite en la capacidad de ofrecer servicios a los visitantes, ha aumentado más del doble: de un 27,2\% (2013) a un $35,8 \%$ (2014), un 43,1\% (2015), un 47,5\% (2016) y finalmente a un 59,9\% en 2017 (Ayuntamiento de Barcelona, 2017) (figura 10).

\subsection{La organización vecinal y las protestas}

En lo que concierne al barrio de La Barceloneta, la inminente aprobación de un nuevo ordenamiento urbanístico, el Plan de Ascensores -aprobado en 2007 y derogado en 2014, que consistía en instalarlos en los edificios de La Barceloneta a costa de eliminar uno de los pisos de cada planta, una normativa que echaría del barrio, a cerca de mil vecinos-, impulsó que surgiesen entidades reivindicativas, como la Asociación de Vecinos la L'Ostia y la plataforma de Afectados en Defensa de La Barceloneta, con el objetivo de unir fuerzas para frenar este proceso. Uno de los miembros de la Asociación L'Ostia justificó así esta postura vecinal: "no queríamos que ningún vecino se fuera de barrio, a parte que, no había ningún estudio ambiental previo, era de locos, porque no todos los edificios de La Barceloneta son iguales, o sea, era un plan que tampoco tenía mucho sentido" (Entrevista, agosto 2016).

También se organizó el movimiento vecinal contestatario Barceloneta diu prou (Barceloneta dice basta), con la finalidad de denunciar y protestar contra la especulación inmobiliaria y el traslado de vecinos a otros barrios.

La agrupación de éstos y otros movimientos barceloneses en asambleas, concentraciones y protestas que han reunidos a centenares de personas, ha puesto de manifiesto la incompatibilidad de los alojamientos turísticos con el descanso vecinal de un barrio repleto de pequeñas viviendas, delimitadas por finas paredes, lo que reduce la privacidad y da paso a los ruidos externos.

En los últimos años los vecinos han marchado por el barrio, para exigir del Ayuntamiento de Barcelona que acabe con este "modelo turístico". Han protestado contra las viviendas turísticas y pedido el fin de sus licencias, y también se oponen al reemplazo de los comercios tradicionales por otros destinados al turismo, a la masificación turística y a la privatización de espacios públicos como plazas, aceras, playas y mercados públicos.

Asimismo, ha impulsado movimientos de resistencia, como es el caso de la campaña Fem plaça! (¡Ocupemos la plaza!) organizada por la red vecinal del distrito Ciutat Vella y ampliamente divulgada en redes sociales afines.

Se trata de un movimiento amplio de espectro social en el que participan los movimientos vecinales de los barrios más afectados, la Federación de Asociaciones de Vecinos de Barcelona (FAVB) de la que forman parte, y muchas otras entidades y sindicatos de la ciudad y del distrito de Ciutat Vella. Estos, y otras entidades agrupadas en la Assemblea de Barris per un Turisme Sostenible (ABTS) instituida a finales de 2015, han llamado a todos los barceloneses a acudir a las marchas organizadas con el objetivo 
de expresar el rechazo de los residentes a políticas que fomentan este «turismo depredador» y reivindicar un cambio de modelo hacia un turismo más sostenible, en el que sea imprescindible el decrecimiento del número de visitantes y de actividades inherentes a esta dinámica, y en su lugar plantee una diversificación de las actividades económicas.

En este entorno se analiza cómo la percepción de los residentes con relación al turismo de masas se ha ido degradando hasta el punto de mostrarse hostil al mismo, como se observa en los slogans que acompañan las protestas vecinales en los últimos años. Frases como "Barcelona no está en venta", "Este barrio no se vende", "My home is not your home", "La Barceloneta is a neighbourhood, not a holiday resort", "Barcelona está en lluita! No als pisos turistics" "El teu turisme assassina el meu barri" (figuras 11 y 12), reflejan el ambiente desfavorable que media entre residentes y foráneos, y la necesidad de buscar alternativas al actual "modelo Barcelona" y todo lo que él conlleva.

Figuras 11 y 12

\section{LA BARCELONETA. PROTESTAS VECINALES DE AGOSTO DE 2016 Y DE 28 DE ENERO DE 2017}
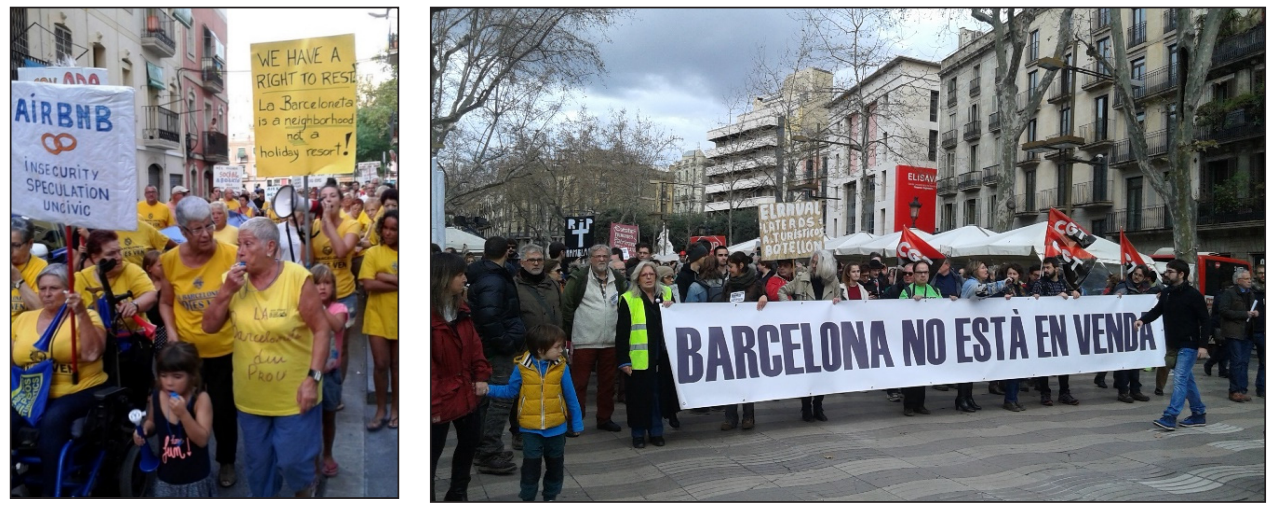

Fuente: Fotos de Manuel-Blas García y Miriam Zaar, agosto de 2016 y enero de 2017.

Este proceso de concienciación, organización y de protestas que, según Neil Smith, representa una lucha no sólo por los nuevos y viejos espacios urbanos sino también por el poder político y simbólico en la determinación del futuro urbano (2012:88), presionó para que la Administración pública local elaborase y pusiese en práctica normativas que limitasen la especulación inmobiliaria y la expulsión vecinal y regulase el espacio público de los barrios más afectados. Algunos de estos proyectos se encuentran todavía en fase de elaboración; otros, como el Plan Especial Urbanístico de Alojamientos Turísticos (PEUAT) ya están en vigor desde comienzos de 2017, y si son bien gestionados pueden traer algunos beneficios a los barrios con mayor afluencia de turistas y como consecuencia a la ciudad de Barcelona. 


\subsection{El Plan Especial Urbanístico de Alojamientos Turísticos (PEUAT), avances y retos}

El Plan Especial Urbanístico de Alojamientos Turísticos se conformó como el primer plan de ordenación y gestión integral de los alojamientos turísticos en el ámbito municipal. Establece como objetivo fundamental: regular la implantación de los alojamientos turísticos en la ciudad de Barcelona, de manera que la actividad económica y la movilidad social que generen sean compatibles con los derechos a la calidad de vida de la ciudadanía barcelonesa, incluyendo el derecho a la vivienda, al descanso y a la intimidad; a la movilidad sostenible, a disfrutar del espacio público, a disponer de una oferta suficiente de servicios, equipamientos y comercio en las proximidades de su hogar, y un medioambiente adecuado (PEUAT, 2017, vol. I, p. 10; Zaar, 2017b:23).

Entre sus prioridades está el impulso de un proceso participativo sobre el modelo turístico de Barcelona, y el desarrollo de un turismo responsable y sostenible que incida tanto en la mejora de la calidad de vida de la ciudadanía como en la experiencia de los visitantes.

Teniendo en cuenta estos objetivos y las reivindicaciones vecinales, el proceso que culminó con la aprobación del PEUAT supone dos avances importantes en el ámbito municipal. Uno, prohibiendo que las viviendas que a fecha de 1 de julio de 2015 estuviesen destinadas a la función residencial se transformen en viviendas de uso turístico, lo que podrá reducir el proceso de gentrificación potencializado por una revalorización de los espacios céntricos de Barcelona y aminorar las graves secuelas dejadas por el deterioro del tejido social de estos barrios. El otro avance se centra en el hecho que a partir de 2019 todas las viviendas de uso turístico, con licencias nuevas o antiguas, deberán, obligatoriamente, agruparse en edificios exclusivos. Medida que se prevé, disminuirá los conflictos en las áreas comunes de los edificios entre vecinos y grupos de turistas 'incívicos'. (PEUAT, 2007, vol. I, p. 104; Zaar, 2017b:31)

Para la elaboración del PEUAT se establecieron cuatro Zonas Específicas (figura 13), con condiciones diferenciadas para la implantación de alojamientos turísticos, determinadas por diferentes variables: a) los planeamientos específicos vigentes; b) la tipología de los tejidos urbanos; c) la presión de las actividades turísticas sobre el espacio público; d) la proporción entre la población flotante y la población residente; y, e) la relación entre las viviendas de uso turístico y el número total de viviendas.

El barrio de La Barceloneta, así como los demás barrios del distrito de Ciutat Vella se sitúan en Zona Específica 1 (ZE-1), en la que se concentra un 56,86\% de los establecimientos turísticos y el 59,71\% de las plazas turísticas, así distribuidas: más del 60\% de las plazas de hoteles, casi el $45 \%$ de las plazas de hoteles-apartamiento, más del $80 \%$ de las plazas destinadas a hostales o pensiones, más del $70 \%$ de plazas de albergues de juventud, el $25 \%$ de las plazas de residencias estudiantiles y casi el $57 \%$ de las plazas de viviendas de uso turístico de la ciudad de Barcelona (PEUAT, 2017, vol. I, p. 103; Zaar, 2017b:24).

Se trata, por lo tanto, de una Zona Específica en la que se agrupan barrios que comprenden las siguientes características: a) mayor concentración de establecimientos y de plazas turísticas; b) proporción entre la población flotante y la población residente superiores al doble de la media municipal $(16,72 \%)$, y relación entre la población flotante y la 


\section{Figura 13 \\ PEUAT. ZONAS ESPECÍFICAS 1, 2, 3 Y 4. BARRIOS BARCELONESES QUE LAS INTEGRAN}

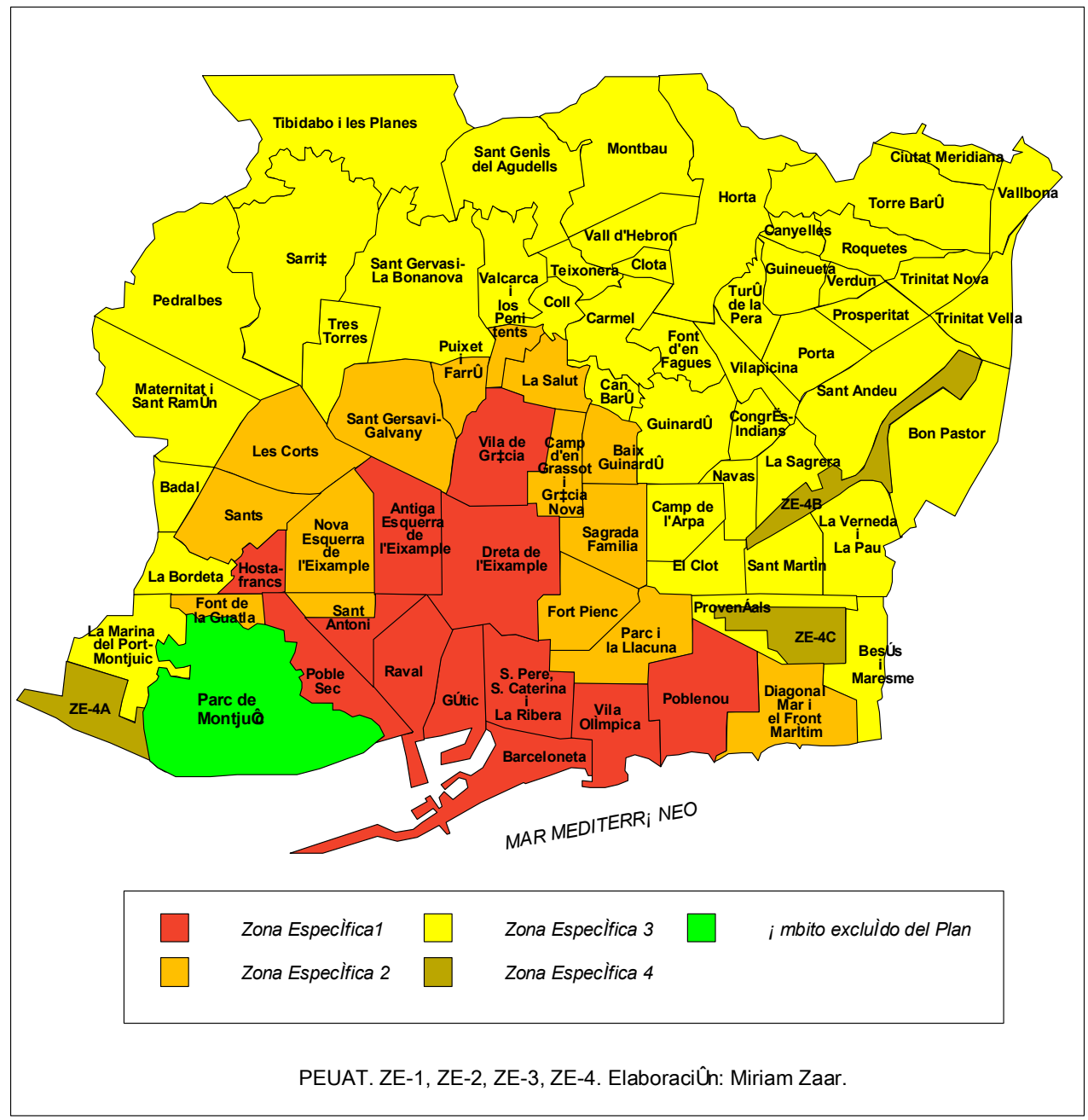

Fuente: Miriam Zaar, 2017b.

total que supera la media municipal del $6,6 \% ; y, c)$ una elevada presión sobre el espacio público, tanto por la alta densidad de las actividades comerciales, de pública concurrencia y turística, como por la existencia de atractivos turísticos (PEUAT, 2017, vol. I, p. 103; Zaar, 2017b:24).

Es por este motivo que, para esta Zona Específica, en la que se incluye el barrio de La Barceloneta, el PEUAT prevé, el mantenimiento de la oferta de alojamientos turísticos 
existentes, no permitiendo nuevas autorizaciones, aunque haya bajas. Esto incluye tanto hoteles, hostales o pensiones, como albergues, Bed \& Breakfast y viviendas de uso turístico.

En lo que concierne específicamente a la concesión de licencias para viviendas de uso turístico, esta misma normativa prohíbe nuevas licencias para la ZE-1, trasladando estas autorizaciones a la Zona Específica 3 (ZE-3).

Sobre los posibles impactos de este Plan en la mejora de la calidad de vida de los barceloneses, se puede afirmar que se trata de un instrumento fundamental en la regulación de las actividades de los alojamientos turísticos, aunque algunas de sus disposiciones contengan decisiones que pongan en cuestión su avance social.

Una de estas disposiciones se refiere al hecho de que su actuación no incide sobre el conjunto de la ciudad en cuanto a las restricciones. Se observa una segregación territorial, en la que se prima la dispersión de las actividades turísticas, en lugar de idear un plan de restricción de las mismas en la ciudad como un 'todo'. Mientras en la ZE-1 prevalece la restricción a nuevas licencias para el establecimiento de 'viviendas turísticas', en la ZE-2 se admite la implantación de nuevos alojamientos turísticos siempre que no superen la densidad máxima de alojamientos y de plazas existentes en la zona, y en la ZE-3 el Plan permite conceder nuevas licencias si no supera la densidad máxima permitida, aunque también contempla crear tantas plazas turísticas cuanto sean las bajas ocurridas en las zonas ZE-1, ZE-2 y en la misma zona (ZE-3).

Otro criterio a partir del que se cuestionan los posibles avances sociales que este Plan puede tener en la ZE-1 y, por adición en el barrio La Barceloneta, es que fija la revisión de las restricciones en el caso de que su relación población flotante-residente se iguale a la ZE-2, que también se caracteriza por una gran concentración de alojamientos turísticos y la presencia de iconos turísticos, como es el entorno de la Basílica de la Sagrada Familia o del Park Güell, lo que le caracteriza como de fuerte presión sobre el espacio público (PEUAT, 2017, vol. I, p. 105; Zaar, 2017b:32). Una normativa que, si es aplicada, puede dejar sin efecto la prohibición de instituir nuevas modalidades de alojamientos turísticos en la ZE1, la más saturada de la ciudad.

Estas imprecisiones hacen que se ponga en duda el alcance de los resultados del PEUAT, tanto con relación a los barrios más saturados como respecto a todo el ámbito municipal. Esto es así porque el Plan, en lugar de promover un 'crecimiento contenido' (solamente para la ZE-3 se prevé una ampliación de 4.030 plazas de alojamiento turístico), debería incentivar una distribución equitativa de las plazas ya existentes.

Del mismo modo, todavía se encuentran pendientes otras normas que reduzcan o eliminen la saturación del espacio público y el impacto del turismo sobre la vida cotidiana de los barceloneses. Para esto sería fundamental que otros alojamientos turísticos como hoteles, hostales, pensiones, hoteles-apartamentos, albergues de juventud y residencias colectivas en los que se hospedan una multitud de visitantes también pasasen por una reglamentación más restrictiva. Sin ésta, el trajín de turistas y maletas, de monociclos (segways o patines eléctricos) y bicis continuarán competiendo con los peatones tanto en las aceras como en las plazas y demás espacios públicos y de ocio. 


\section{CONCLUSIÓN. LA RELACIÓN ENTRE LOS IMPACTOS DE LA ACTIVIDA- DES TURÍSTICAS EN EL BARRIO DE LA BARCELONETA Y EL ÍNDICE DE RECHAZO HACIA LOS VISITANTES}

Contextualizada la problemática que analiza las contradicciones que conforman el 'modelo Barcelona', en el que sus éxitos como ciudad mercancía se contraponen a la principal función de la ciudad, como lugar de desarrollo de la vida, es necesario elaborar un análisis que vincule algunas de las aportaciones teóricas sobre la relación turista-residente con la investigación presentada. En este empeño se llega a tres conclusiones básicas:

$1^{\circ}$. Que el impacto de las actividades turísticas sobre la población local en las zonas centrales de la ciudad de Barcelona, como el barrio de La Barceloneta, se caracteriza, por un turismo masivo fomentado por los paquetes turísticos asociados a los vuelos low cost y a plataformas como Airbnb y Homeaway, cuyos servicios impulsan constantemente el flujo continuo de turistas, lo que está produciendo un profundo cambio económico, social y cultural del lugar.

Como parte de esta dinámica existen, según intereses diversos, dos principales puntos de vista contradictorios: mientras los empresarios, agentes turísticos y ayuntamientos -aunque éstos últimos toman actitudes diferentes dependiendo de su ideología política- abogan a favor de mantener políticas que incentiven el aumento continuo de turistas, ya que, según su justificación, los visitantes dinamizan la economía local, basada en los servicios y fomentan el empleo en este sector, la población residente clama por un decrecimiento turístico o, en último caso, una reestructuración del mismo, mediante el que se disuaría el turismo de sol y playa y se primaría un turismo de mayor calidad, volcado, por ejemplo, al ámbito arquitectónico, artístico y cultural.

$2^{\circ}$. Que varios barrios de la ciudad de Barcelona, como el de La Barceloneta, se encuentran en fase de consolidación turística (destinos maduros). $\mathrm{Si}$, por un lado, el aumento del número de turistas se ha mantenido en los últimos años a causa de un importante esfuerzo de marketing que ha ido recalificando sus atractivos, a través de la promoción de eventos y creación de iconos turísticos, por otro, su intenso flujo está generando un gran descontento entre sus residentes e incluso una actitud de rechazo hacia las actividades turísticas y a los turistas.

$3^{\circ}$. Como última faceta de este proceso se destaca que los resultados obtenidos en este análisis sobre el barrio de La Barceloneta coinciden con los del estudio de George Doxey sobre la teoría de la causalidad entre visitantes y residentes irritados publicada en 1975 . Aunque desconocemos estudios anteriores sobre el nivel de afectación del turismo en el vecindario de La Barceloneta, nuestro análisis posibilita llegar a los siguientes corolarios en lo que concierne al índice de irritabilidad de los residentes hacia los foráneos:

- Existe un alto nivel de irritación entre los vecinos de los barrios del Districto de Ciutat Vella y como consecuencia, en el barrio de La Barceloneta, vinculado a diversos procesos que incluyen: la especulación inmobiliaria y la pérdida de la vivienda; el reemplazo de los comercios locales por cadenas comerciales que atienden la demanda turística; la disputa entre vecinos y visitantes para la utilización del transporte público y del espacio público, que en algunas áreas también está tomado por restaurantes, bares y otros negocios. 
- Se trata de una coyuntura que ha desterritorializado a los residentes en lo que se refiere al su modo de vida y a su cotidiano, ya que a menudo sus viviendas son reemplazadas por viviendas de uso turístico y los espacios comunes que solían frecuentar se encuentran abarrotados de visitantes ruidosos cuyos horarios diarios discrepan de los suyos. Un escenario que ha fomentado, un sentimiento de irritabilidad que, en el caso de que no sea mitigado a través de aplicación de normativas, podría, en algunos casos, derivar a una agresión abierta a los visitantes.

Se concluye, corroborando los estudios anteriores realizados por George Doxey, Richard Butler y otros autores. El análisis realizado en el barrio de La Barceloneta comprueba que existe una fuerte relación entre la fase de desarrollo turístico y el modo como la población local percibe los impactos turísticos. El alto índice de irritabilidad constatado entre los vecinos refleja la masificación turística, la destrucción del tejido socio económico del barrio y la movilización vecinal hacia posibles soluciones, entre las que se encuentran, por ejemplo, las denuncias de las viviendas de uso turístico ilegales, las manifestaciones multitudinarias y las presiones realizadas ante el Ayuntamiento de Barcelona para que la gestión de las actividades turísticas tenga en cuenta las necesidades y demandas vecinales. Uno de los resultados ha sido la elaboración y la aprobación del PEUAT, aunque existen otros procesos pendientes de reglamento, como el de la apropiación del espacio público por las actividades turísticas.

Además, la paulatina pérdida identitaria del barrio y de sus singularidades, es un proceso que requiere acciones públicas municipales que, frente a la ciudad-mercancía, tengan como cometido priorizar los derechos individuales y colectivos de los ciudadanos, para hacer viable la 'reproducción ampliada de la vida'.

\section{AGRADECIMIENTOS}

Agradecemos a los Profesores Eméritos de la Universidad de Barcelona, Horacio Capel y Mercedes Tatjer la lectura atenta de este original y sus comentarios.

\section{BIBLIOGRAFÍA}

AYUNTAMIENTO DE BARCELONA (1973): «Ponencia del Pla de Ordenación Urbana. Explotación del Padrón de 1965». En Tatjer, M. La Barceloneta del siglo XVIII al Plan de La Ribera. Barcelona, Libros de La Frontera.

AYUNTAMIENTO DE BARCELONA (2017): Plan Especial Urbanístico de Alojamientos Turísticos (PEUAT), marzo de 2017, vol. I.

ARCHER B. y COOPER, C. (2002): «Os impactos Negativos e positivos do turismo». En THEOBALD, W. (Ed.). Turismo Global. São Paulo, Senac, pp. 85-102.

BLANCO, A., BLÀZQUEZ, M. y MÍNGUEZ, C. (2017): «Claves de la reestructuración turística de la ciudad». En Álvarez F. et al. (Eds.), Actas del XXV Congreso Nacional de la Asociación de Geógrafos Españoles (Naturaleza, Territorio y Ciudad en un Mundo Global), Madrid, 25-27 de octubre, pp. 1.516-1.524.

BORJA, J. (2005): «Revolución y contrarrevolución en la ciudad global». Biblio 3W, Revista Bibliográfica de Geografía y Ciencias Sociales, Universidad de Barcelona, Vol. X, ${ }^{\circ}$ 578, 20 de abril de 2005. Disponible en <http://www.ub.edu/geocrit/b3w-578.htm>. 
CAPEL, H. (2005): El modelo Barcelona: un examen crítico. Barcelona, Ediciones del Serbal.

CAPEL, H. (2007): «El debate sobre la construcción de la ciudad y el llamado «Modelo Barcelona»», en Scripta Nova. Revista Electrónica de Geografía y Ciencias sociales, 15 de febrero de 2007, vol. XI, $n^{\circ}$ 233. Universidad de Barcelona. Disponible en, $<$ http://www.ub.edu/geocrit/sn/sn-233.htm>

CASGRAIN, A y JANOSCHKA, M. (2013): «Gentrificación y resistencia en las ciudades latinoamericanas. El ejemplo de Santiago de Chile». Andamios. Revista de Investigación Social, vol. 10, n 22, mayo-agosto, pp. 19-44.

DELGADO, M. y MALET, D. (2007): «El espacio público como ideología». Jornadas Marx siglo XXI, Universidad de la Rioja, Logroño, diciembre 2007. Disponible en <https://antropologiadeoutraforma.files.wordpress.com/2014/03/el-espacio-pc3bablico-como-ideologc3ada-manuel-delgado.pdf>

DIEDRICH, A. y GARCIA-BUADES, E. (2009): «Local perceptions of tourism as indicators of destination decline», Tourism Management, vol. 30, $\mathrm{n}^{\circ}$ 4, pp. 512-521.

DOXEY, G.V. (1975): «A causation theory of visitor-resident irritants, methodology and research inferences. The impact of tourism», Sixth annual conference proceedings of the Travel Research Association, San Diego, pp. 195-198.

GONZÁLEZ HERRERA, M.R. y FONT ARANDA, M. (2013): «Rapid assessment of tourism impacts through community participation. A pilot study in Cuba for projecting new strategies of management», Current Urban Studies, vol. 1, n 3, pp. 36-47.

HARVEY, D. (2004): «El 'nuevo' imperialismo. Acumulación por desposesión». Socialist Register, $\mathrm{n}^{\mathrm{o}}$ 42, pp. 99-129.

HARVEY, D. (2013): Ciudades Rebeldes. Del derecho a la ciudad a la revolución urbana. Madrid, Ediciones Akal.

HEREDERO, O. y CHAVES, M.A (2015): «Las asociaciones «marca producto» y «marca ciudad» como estrategia de «city branding». Una aproximación a los casos de Nueva York, París y Londres». Área Abierta. Revista de Comunicación Audiovisual y Publicitaria, vol. 15, $\mathrm{n}^{\circ}$ 2, julio 2015, pp. 63-76.

HIERNAUX, D. y GONZÁLEZ, C.I. (2014): «Turismo y gentrificación: pistas teóricas sobre una articulación». Revista de Geografía Norte Grande, vol. 58, pp. 55-70.

LÓPEZ PALOMEQUE, F. (2015): "Barcelona, de ciudad con turismo a ciudad turística. Notas sobre un proceso complejo e inacabado". Documents d'Anàlisi Geogràfica, vol. 61, no 3 , pp. 483-506.

PEARCE, Philip (2002): «A relação entre residentes e turistas: literatura sobre pesquisas e diretrizes de gestão». En THEOBALD, W. Turismo Global. São Paulo, Senac, pp. 145-164.

RAMÓN CARDENA, J. (2012): Actitudes de los residentes hacia el turismo en destinos turísticos consolidados: el caso de Ibiza. Tesis doctoral. Palma de Mallorca: Universidad de las Islas Baleares.

SMITH, N. (2012): La nueva frontera urbana. Ciudad revanchista y gentrificación. Traducción: Verónica Hendel. Madrid, Traficantes de Sueños. Versión original 1996.

SMITH, V. (1992): «Anfitriones e invitados», Antropología del turismo. Madrid, Endymion, pp. 36-38. Versión original 1978. 
TAPIA, M.C. (2013): «Transformación del puerto de Barcelona ¿Adiós a la planificación urbana?», en Biblio 3W. Revista Bibliográfica de Geografía y Ciencias Sociales. Universidad de Barcelona, 15 de noviembre de 2013, vol. XVIII, n 1049(04). Disponible en <http://www.ub.es/geocrit/b3w-1049/b3w-1049-04.htm>.

TATJER MIR, M. (1973): La Barceloneta del siglo XVIII al Plan de La Ribera. Barcelona, Libros de La Frontera.

TATJER MIR, M. (2012): Els banys de mar a Catalunya. Barcelona, Editorial Albertí.

TATJER MIR, M. (2015): «La Barceloneta com a centre de producció i aprovisionament naval, 1750-1850», Quaderns d'Història, n 22, pp. 67-86.

VILANOVA, J. M. (2012): «MdSM, Barcelona, y el mar», en Biblio 3W. Revista Bibliográfica de Geografía y Ciencias Sociales. Universidad de Barcelona, 20 de mayo de 2012, vol. XVII, no 976 (5). Disponible en <http://www.ub.es/geocrit/b3w-976/b3w-976-5.htm>

WEAVER, D. y LAWTON, L. (2001): «Resident Perceptions in the Urban-Rural Fringe», en Annals of Tourism Research, vol. 28, n 2, pp. 439-458.

ZAAR, M.H. (2017a): «El análisis del territorio desde una 'totalidad dialéctica'. Más allá de la dicotomía ciudad-campo, de un 'par dialéctico' o de una 'urbanidad rural'», Espaço e Economia, 10 | 2017, año v, nº 10. Disponible en <http://espacoeconomia. revues.org/2981>.

ZAAR, M.H. (2017b): «El derecho a la vivienda en el contexto del Plan Especial Urbanístico de Alojamientos Turísticos (PEUAT) de Barcelona y de sus planes antecesores», Biblio 3W. Revista Bibliográfica de Geografía y Ciencias Sociales. Universidad de Barcelona, 5 septiembre 2017, vol. XXII, n 1.210 . Disponible en <http://www.ub.edu/ geocrit/b3w-1210.pdf>.

\section{Artículos de Periódicos y Páginas Webs}

AYUNTAMIENTO DE BARCELONA (2016a): Impacte del lloguer vacacional en el mercat de lloguer residencial de Barcelona. Pla Estratègic de Turisme Barcelona 2020. <https://ajuntament.barcelona.cat/turisme/sites/default/files/160921_informe_ impacte_lloguer_vacacional_0.pdf $>$ [12-8-2018].

AYUNTAMIENTO DE BARCELONA (2016b): Percepció del turisme a Barcelona. Presentació de resultados. Disponible en <https://ajuntament.barcelona.cat/turisme/ sites/default/files/documents/r16002_percepcio_del_turisme_informe.pdf [15-7-2018].

AYUNTAMIENTO DE BARCELONA (2016c): Anuario Estadístico de la ciudad de Barcelona. Disponible en <http://www.ben.cat/estadistica/castella/dades/anuari/cap02/ C020102.htm> [10-7-2018].

AYUNTAMIENTO DE BARCELONA (2017): Percepció del Turisme a Barcelona. Presentació de resultados, 2017. Disponible en <https://ajuntament.barcelona.cat/turisme/ sites/default/files/percepcio_del_turisme_2017_informe_0.pdf> [24-7-2018].

AYUNTAMIENTO DE BARCELONA (2018a): La Barceloneta. Ciutat Vella. Disponible en <http://www.bcn.cat/estadistica/castella/documents/barris/03_CV_Barceloneta_2018.pdf $>$.

AYUNTAMIENTO DE BARCELONA (2018b): <http://www.bcn.cat/estadistica/castella/ dades/economia/teoh/evo/t22.htm> [30-7-2018]. 
BUSINESS INSIDER UK (2017): Disponible en <http://uk.businessinsider.com/the-most-visited-cities-around-the-world-in-2017-2017-9/\#2-london-uk-20-million-international-visitors-29> [28-7-2018].

CASTÁN, P. (2014): «Los efectos negativos del éxito turístico de Barcelona. La Barceloneta en pie de guerra», El Periódico, 21 de agosto de $2014<$ http://www.elperiodico. com/es/barcelona/20140820/la-barceloneta-en-pie-de-guerra-3462327> [10-7-2018].

GOZZER ARIAS, S. (2014): «Estaba tan hasta de que llamaran de noche que le tiré un cubo de agua», El País, 21 de agosto de 2014. <http://ccaa.elpais.com/ccaa/2014/08/21/ catalunya/1408657212_656214.html?rel=rosEP> [10-7-2018].

HOSTELTUR, 13/11/2017: Disponible en <https://www.hosteltur.com/125047_londresestambul-barcelona-ciudades-donde-turistas-gastan.html> [10-7-2018].

MASTERCARD 2015 GLOBAL DESTINATIONS CITIES INDEX : Disponible en $<$ https://newsroom.mastercard.com/wp-content/uploads/2015/06/MasterCard-GDCI2015-Final-Report1.pdf > [20-6-2018].

MASTERCARD 2016 GLOBAL DESTINATIONS CITIES INDEX : Disponible en $<$ https://newsroom.mastercard.com/wp-content/uploads/2016/09/FINAL-Global-Destination-Cities-Index-Report.pdf> [20-6-2018].

MONTANER, José María (2014): «La burbuja hotelera. En el Eixample se conceden más de mil licencias de pisos turísticos al año, con el consiguiente riesgo de mutación social», El País, 10 de abril de 2014. Disponible en <http://ccaa.elpais.com/ ccaa/2014/04/09/catalunya/1397066103_197640.html> [10-7-2018].

ORGANIZACIÓN MUNDIAL DE TURISMO: Disponible en <http://media.unwto.org/es/ press-release/2018-01-15/resultados-del-turismo-internacional-en-2017-los-mas-altos-en-siete-anos $>$ [10-9-2018]. 